\title{
Self rated health and mortality: a long term prospective study in eastern Finland
}

\author{
S Heistaro, P Jousilahti, E Lahelma, E Vartiainen, P Puska
}

\begin{abstract}
Study objective-To assess the relation between self rated health and mortality over a period of 23 years, taking into account medical history, cardiovascular risk factors, and education at the beginning of the follow up.

Design-A cohort of random population samples. The baseline studies included a self administered questionnaire and a health examination. Mortality data were collected from the national mortality register using personal identification numbers.
\end{abstract}

Setting-The provinces of North Karelia and Kuopio in eastern Finland.

Participants-Random samples of working age people $(n=21302)$ from the population register.

Main results-For self rated health, the age adjusted poor to good relative risk for all cause mortality was 2.36 (95\% confidence intervals $2.10,2.64)$ for men and $1.90(1.63,2.22)$ for women, and for cardiovascular mortality $2.29(1.96,2.68)$ for men and $2.34(1.84,2.96)$ for women. Adjusted for selected potentially fatal diseases from the subjects' medical histories, cardiovascular disease risk factors, and education, the corresponding relative risks for all cause mortality were 1.66 $(1.47,1.88)$ for men and $1.50(1.26,1.78)$ for women, and for cardiovascular mortality $1.54(1.29,1.82)$ for men and 1.63 $(1.26,2.10)$ for women. The association between self rated health and mortality attributable to external causes was fairly strong.

Conclusions-Poor self rated health is a strong predictor of mortality, and the association is only partly explained by medical history, cardiovascular disease risk factors, and education.

(F Epidemiol Community Health 2001;55:227-232)

Institute, Helsinki,

Finland

S Heistaro

P Jousilahti

E Vartiainen

P Puska

University of Helsinki, Helsinki, Finland

E Lahelma

Correspondence to:

Dr Heistaro, National Public

Health Institute, Departmen

of Health and Disability,

Mannerheimintie 166, 00300

Helsinki, Finland

(sami.heistaro@ktl.fi)

Accepted for publication

15 November 2000 health and mortality, because other self reports on health may have the same personal bias as self rated health. They concluded that poor self rated health was mainly associated with mortality because of its association with cardiovascular diseases. Others ${ }^{17}$ have suggested that psychological factors might expose people to coronary heart disease, thus explaining the strong association. Mortality differences seem to be greater in studies with a short follow up. ${ }^{611}$ The literature suggests that we should have a better understanding of the mechanisms by which self rated health predicts mortality. We ask whether and to what extent can the association between self rated health and mortality be explained by different background factors, and does the association equally concern different main causes of death-that is, cardiovascular and external causes, as well as total mortality?

This paper considers these questions by assessing the relation between self rated health and mortality over a period of up to 23 years in eastern Finland, taking into account medical history, cardiovascular risk factors, and education at the starting point of the follow up.

\section{Methods}

The high coronary heart disease rates in Finland at the beginning of the $1970 \mathrm{~s}^{18}$ led to the launch of the North Karelia Project in 1972. The aim was to lower the high coronary mortality rates in the province of North Karelia by implementing a comprehensive community-based intervention programme. ${ }^{19}$ Using population surveys, data were collected on cardiovascular disease risk factors, socioeconomic variables, medical history, health behaviour, and self reported health.

In 1972 and 1977 cross sectional surveys were conducted in the provinces of North Karelia and Kuopio. Independent random samples, $6.6 \%$ (13.2\% in the city of Joensuu) of the population born during 1913-47, were drawn from the population register in both areas. In 1977 an additional $6.6 \%$ random sample of the population born between 1948 and 1952 was drawn in North Karelia. The original samples from the two surveys consisted of 13538 men and 13661 women, and participation rates were $86.5 \%$ and $90.1 \%$ for men and women respectively. Those who had been randomly selected in both surveys (1972 and 1977) were excluded from the 1977 sample in this study (341 men and 394 women). The subjects who had missing values in self rated health, education, smoking, serum cholesterol, systolic blood pressure, body mass index, or leisure time physical activity - that is, 
Table 1 Self rated health and other variables by sex (1972 and 1977)

\begin{tabular}{lll}
\hline & $\begin{array}{l}\text { Men } \\
(n=10363)\end{array}$ & $\begin{array}{l}\text { Women } \\
(n=10939)\end{array}$ \\
\hline Self rated health (\%) & & \\
Very good & 8.4 & 5.8 \\
Quite good & 33.3 & 33.9 \\
Average & 40.9 & 43.8 \\
Quite poor & 15.3 & 14.7 \\
Very poor & 2.1 & 1.7 \\
Myocardial infarction (\%) & 2.5 & 0.8 \\
Stroke (\%) & 0.7 & 0.4 \\
Heart failure (\%) & 5.3 & 6.0 \\
Angina pectoris (\%) & 5.1 & 3.8 \\
Bronchial asthma (\%) & 1.5 & 1.4 \\
Emphysema/bronchitis (\%) & 6.7 & 3.7 \\
Rheumatoid arthritis (\%) & 3.3 & 5.5 \\
Smoking (\%) & 49.6 & 13.1 \\
Leisure time physical activity (\%) & & \\
Low & 31.9 & 47.2 \\
Moderate & 52.2 & 10.1 \\
High & 15.9 & \\
Education (\%) & & 28.4 \\
Low & 22.4 & 35.1 \\
Middle & 37.7 & 36.5 \\
High & 39.9 & $43.4(10.6)$ \\
Age (y) (SD) & $42.4(10.4)$ & $6.6(1.4)$ \\
Serum cholesterol (mmol/l) (SD) & $6.7(1.3)$ & $144.4(24.3)$ \\
Systolic blood pressure (mm Hg) (SD) & $145.3(19.6)$ & $26.1(4.6)$ \\
Body mass index (kg/m ${ }^{2}$ ) (SD) & $25.8(3.4)$ & \\
\hline
\end{tabular}

1010 men and 978 women-were also excluded from the analyses. Thus 10363 men and 10939 women were included.

The surveys were carried out by mailing a self administered questionnaire to the subjects. Thereafter the respondents had a health examination, in which a trained research team at the local health centre carried out standardised risk factor measurements, for example, blood pressure, height, weight, and blood samples. Serum cholesterol was analysed centrally in the laboratory of the National Public Health Institute.

Table 2 Self rated health in relation to mortality between 1972/1977-1995: relative risks (RR) with 95\% confidence intervals (CI). "Good" health $=1.00$

\begin{tabular}{|c|c|c|c|}
\hline & & $\begin{array}{l}M e n \\
R R(95 \% C I)\end{array}$ & $\begin{array}{l}\text { Women } \\
\text { RR }(95 \% \text { CI) }\end{array}$ \\
\hline \multicolumn{2}{|c|}{ All cause mortality } & $\mathrm{n}=2701$ & $\mathrm{n}=1424$ \\
\hline \multirow[t]{2}{*}{ Model 1} & Average & $1.50(1.36,1.67)$ & $1.27(1.10,1.46)$ \\
\hline & Poor & $2.36(2.10,2.64)$ & $1.90(1.63,2.22)$ \\
\hline \multirow[t]{2}{*}{ Model 2} & Average & $1.31(1.18,1.45)$ & $1.17(1.01,1.35)$ \\
\hline & Poor & $1.69(1.50,1.91)$ & $1.50(1.27,1.78)$ \\
\hline \multirow[t]{2}{*}{ Model 3} & Average & $1.29(1.16,1.44)$ & $1.17(1.01,1.35)$ \\
\hline & Poor & $1.66(1.47,1.88)$ & $1.50(1.26,1.78)$ \\
\hline \multicolumn{2}{|c|}{ CVD mortality } & $\mathrm{n}=1448$ & $\mathrm{n}=692$ \\
\hline \multirow[t]{2}{*}{ Model 4} & Average & $1.53(1.32,1.77)$ & $1.46(1.16,1.84)$ \\
\hline & Poor & $2.29(1.96,2.68)$ & $2.34(1.84,2.96)$ \\
\hline \multirow[t]{2}{*}{ Model 5} & Average & $1.47(1.27,1.71)$ & $1.40(1.11,1.76)$ \\
\hline & Poor & $1.89(1.60,2.23)$ & $1.93(1.50,2.47)$ \\
\hline \multirow[t]{2}{*}{ Model 6} & Average & $1.30(1.12,1.51)$ & $1.29(1.03,1.63)$ \\
\hline & Poor & $1.56(1.32,1.85)$ & $1.63(1.27,2.10)$ \\
\hline \multirow[t]{2}{*}{ Model 7} & Average & $1.29(1.11,1.49)$ & $1.29(1.02,1.63)$ \\
\hline & Poor & $1.54(1.29,1.82)$ & $1.63(1.26,2.10)$ \\
\hline \multicolumn{2}{|c|}{ External causes mortality } & $\mathrm{n}=316$ & $\mathrm{n}=83$ \\
\hline \multirow[t]{2}{*}{ Model 8} & Average & $1.42(1.10,1.85)$ & $1.88(1.10,3.22)$ \\
\hline & Poor & $1.73(1.23,2.42)$ & $1.76(0.87,3.57)$ \\
\hline \multirow[t]{2}{*}{ Model 9} & Average & $1.40(1.08,1.82)$ & $1.83(1.07,3.14)$ \\
\hline & Poor & $1.66(1.18,2.35)$ & $1.67(0.81,3.41)$ \\
\hline
\end{tabular}

$\mathrm{n}=$ Number of deaths in the cohort between 1972/1977 and 1995. CVD = cardiovascular diseases. Models 1 to 3 were adjusted for age (continuous variable) and survey year and, furthermore, models 2 and 3 for myocardial infarction, stroke, heart failure, angina pectoris, bronchial asthma, emphysema/bronchitis, rheumatoid arthritis, smoking, serum total cholesterol, systolic blood pressure, body mass index, and leisure time physical activity and, furthermore, model 3 for education. Models 4 to 7 were adjusted for age (continuous variable) and survey year and, furthermore, models 5 to 7 for myocardial infarction, stroke, heart failure, and angina pectoris and, furthermore, models 6 and 7 for smoking, serum total cholesterol, systolic blood pressure, body mass index, and leisure time physical activity and, furthermore, model 7 for education. Models 8 and 9 were adjusted for age (continuous variable) and survey year and, furthermore, model 9 for education.
In the questionnaire the subjects were asked to rate their present health status along a five point scale: very good, quite good, average, quite poor, and very poor. This health measure has proved to be a reliable one in test-retest analysis, ${ }^{20} 21$ and it seems to form a continuum from poor through average to good in relation to most risk factors and ill health indicators. ${ }^{22}$ The distribution of the responses is given in table 1 , in which we present background information on the sample. In the analyses, we classified the respondents into three groups according to self rated health by combining those who responded "very good" or "quite good" to "good", and those who responded "quite poor" or "very poor" to "poor".

Data on the subjects' medical history were collected by asking if a doctor had diagnosed or treated certain diseases during the past 12 months, namely, myocardial infarction, stroke, heart failure, angina pectoris, bronchial asthma, emphysema/bronchitis, and rheumatoid arthritis. The questionnaire also asked the respondents' smoking status. Those who reported they were current smokers or had stopped smoking less than six months before the survey were regarded as smokers, all others were regarded as non-smokers. We sorted the respondents into three groups (low, moderate, high) according to self reported average leisure time physical activity.

Education was measured as the total number of school years, defined as containing all education beginning with elementary school. Because the mean length and the structure of the education system had changed markedly during the 20th century, we divided the respondents into educational tertiles according to year of birth by sex, tertile 1 having the lowest education.

Mortality data until 1985 and 1995 were collected from the national mortality register using personal identification numbers. Cardiovascular disease mortality and external causes mortality were analysed separately, in addition to all cause mortality. The statistical analyses were done using SAS programs ${ }^{23}$ and proportional hazards (Cox) regression. All the models were controlled for age and study year. Self rated health was added into the models as dummies (good, average, poor), using the "good" group as a reference. Age, serum cholesterol, systolic blood pressure, and body mass index (weight $(\mathrm{kg}) /$ height $(\mathrm{m})^{2}$ ) were used as continuous variables. Adding the squared terms of serum cholesterol and body mass index in the models did not affect the association between self rated health and mortality.

\section{Results}

For self rated health, the age adjusted "poor" to "good" relative risk for all cause mortality was 2.36 (95\% confidence intervals $2.10,2.64)$ for men and $1.90(1.63,2.22)$ for women, and for cardiovascular mortality $2.29(1.96,2.68)$ for men and $2.34(1.84,2.96)$ for women (table 2$)$. Adjusted for the selected potentially fatal diseases from the medical history, cardiovascular disease risk factors, and education, the 
Table 3 Covariates from the full models (models 3 and 7) in relation to mortality between 1972/1977-1995: relative risks (RR) with $95 \%$ confidence intervals (CI)

\begin{tabular}{|c|c|c|c|c|}
\hline & \multicolumn{2}{|l|}{$\begin{array}{l}\text { Men } \\
R R(95 \% C I)\end{array}$} & \multicolumn{2}{|l|}{$\begin{array}{l}\text { Women } \\
R R(95 \% \text { CI) }\end{array}$} \\
\hline & All cause mortality & CVD mortality & All cause mortality & CVD mortality \\
\hline Age $(y)$ & $1.08(1.07,1.08)$ & $1.09(1.08,1.10)$ & $1.09(1.08,1.10)$ & $1.11(1.09,1.12)$ \\
\hline Survey year $(1972=1,1977=2)$ & $1.03(0.94,1.12)$ & $0.95(0.85,1.07)$ & $1.03(0.91,1.16)$ & $1.17(0.97,1.40)$ \\
\hline Average $v$ good SRH & $1.29(1.16,1.44)$ & $1.29(1.11,1.49)$ & $1.17(1.01,1.35)$ & $1.29(1.02,1.63)$ \\
\hline Poor $v$ good SRH & $1.66(1.47,1.88)$ & $1.54(1.29,1.82)$ & $1.50(1.26,1.78)$ & $1.63(1.26,2.10)$ \\
\hline Myocardial infarction (yes/no) & $2.12(1.81,2.48)$ & $2.97(2.47,3.57)$ & $1.48(1.06,2.08)$ & $2.08(1.41,3.05)$ \\
\hline Stroke (yes/no) & $1.25(0.91,1.72)$ & $1.10(0.72,1.69)$ & $0.92(0.55,1.54)$ & $1.11(0.62,1.99)$ \\
\hline Heart failure (yes/no) & $1.30(1.15,1.47)$ & $1.31(1.11,1.53)$ & $1.47(1.26,1.70)$ & $1.66(1.37,2.02)$ \\
\hline Angina pectoris (yes/no) & $1.00(0.87,1.14)$ & $1.10(0.92,1.30)$ & $1.09(0.88,1.34)$ & $1.19(0.92,1.56)$ \\
\hline Bronchial asthma (yes/no) & $1.26(1.00,1.58)$ & & $0.98(0.68,1.42)$ & \\
\hline Emphysema/bronchitis (yes/no) & $1.11(0.99,1.26)$ & & $0.97(0.75,1.24)$ & \\
\hline Rheumatoid arthritis (yes/no) & $1.06(0.91,1.25)$ & & $1.07(0.91,1.27)$ & \\
\hline Smoking (yes/no) & $2.09(1.93,2.27)$ & $1.95(1.75,2.17)$ & $2.07(1.77,2.42)$ & $2.56(2.04,3.22)$ \\
\hline Serum cholesterol $(\mathrm{mmol} / \mathrm{l})$ & $1.08(1.05,1.11)$ & $1.20(1.16,1.25)$ & $1.01(0.97,1.05)$ & $1.10(1.05,1.16)$ \\
\hline Systolic blood pressure $(\mathrm{mm} \mathrm{Hg})$ & $1.01(1.01,1.01)$ & $1.01(1.01,1.02)$ & $1.01(1.01,1.01)$ & $1.02(1.01,1.02)$ \\
\hline Body mass index $\left(\mathrm{kg} / \mathrm{m}^{2}\right)$ & $1.00(0.99,1.02)$ & $1.03(1.01,1.04)$ & $1.01(0.99,1.02)$ & $1.01(0.99,1.03)$ \\
\hline Leisure time physical activity` & $0.89(0.83,0.95)$ & $0.93(0.85,1.02)$ & $0.86(0.78,0.94)$ & $0.84(0.73,0.96)$ \\
\hline Education (low, middle, high) & $0.95(0.91,1.00)$ & $0.95(0.89,1.02)$ & $1.00(0.93,1.07)$ & $0.99(0.90,1.09)$ \\
\hline
\end{tabular}

$\mathrm{CVD}=$ cardiovascular diseases, $\mathrm{SRH}=$ self rated health. ${ }^{\star}$ Low, moderate, high.

corresponding relative risks for all cause mortality were $1.66(1.47,1.88)$ for men and $1.50(1.26,1.78)$ for women, and for cardiovascular mortality $1.54(1.29,1.82)$ for men and $1.63(1.26,2.10)$ for women. A gradient from "good" through "average" to "poor" self rated health in relation to all cause and cardiovascular mortality was found. Among women the relative risks for the "average" group were only marginally significant after the adjustments. Table 3 presents the relative risks for the covariates in the full models for all cause and cardiovascular mortality.

The association between self rated health and mortality attributable to external causes was fairly strong among men, and the adjusted "poor" to "good" relative risk was 1.66 (1.18, 2.35). For women the relative risk for "average" self rated health, $1.83(1.07,3.14)$, was greater than that for "poor" health, $1.67(0.81$, 3.41).

Table 4 presents the relative risks for mortality between 1972/1977-1985 for self rated health. Among men the association between self rated health and mortality was slightly stronger than during the longer follow up 1972/1977-1995. The relatively small number of deaths among women may explain that the association was not so strong as during the longer follow up. Combining men and

Table 4 Self rated health in relation to mortality between 1972/1977-1985: relative risks (RR) with 95\% confidence intervals (CI). "Good" health $=1.00$

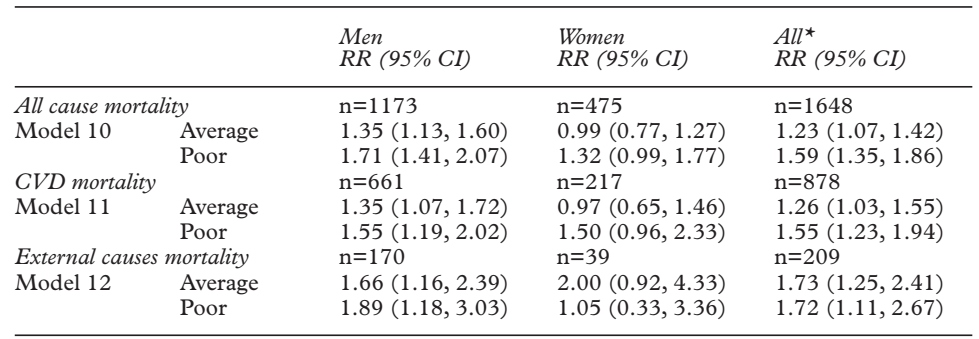

*Adjusted also for sex. $\mathrm{n}=$ Number of deaths in the cohort between 1972/1977 and 1985. CVD = cardiovascular diseases. Model 10 was adjusted for age (continuous variable), survey year, myocardial infarction, stroke, heart failure, angina pectoris, bronchial asthma, emphysema/bronchitis, rheumatoid arthritis, smoking, serum total cholesterol, systolic blood pressure, body mass index, leisure time physical activity, and education. Model 11 was adjusted for age (continuous variable), survey year, myocardial infarction, stroke, heart failure, angina pectoris, smoking, serum total cholesterol, systolic blood pressure, body mass index, leisure time physical activity, and education. Model 12 was adjusted for age (continuous variable), survey year, and education. women, the association between self rated health and all cause and cardiovascular mortality was statistically significant, and there was a gradient from "good" through "average" to "poor" health.

\section{Discussion}

In this study self rated health strongly predicted mortality in a randomly selected population cohort in eastern Finland. This association was only partly explained by medical history, cardiovascular disease risk factors, and education. The relation was strong among both men and women, and it was evident during a shorter as well as a longer follow up. A clear gradient was found from "good" through "average" to "poor" self rated health in relation to all cause and cardiovascular mortality. These results are in line with several earlier studies published in recent years. ${ }^{4-15}$ The exact questions, settings, populations, and background variables used in these studies vary greatly, but in most studies the basic finding has been similar - that is, self rated health is associated with subsequent mortality even when the models are adjusted for several background variables. Large samples, a wide age range of the cohort, a long follow up with two assessing points, reliable links with the mortality register, specific causes of mortality, data on several self reported medical history items, and measured cardiovascular disease risk factors were the specific advantages of this study.

The association between self rated health and mortality can be understood so that certain conditions make one feel unhealthy, and these conditions also cause mortality. However, after adjusting for several background variables something seems to remain unexplained.

It has been suggested that the predictive value of self rated heath could be partly caused by a "healthy attitude" in life: the individual attempts to achieve the high level of health that one has chosen and works for. ${ }^{8}$ Thus self rated health may reflect the level of life control. Moreover, it may indicate the respondent's personal, possibly unconscious, assessment of 
his or her life expectancy, ${ }^{8}$ taking into account all that he or she knows to have an effect on health and mortality. For an outside health professional, even several specific questions might not be enough to collect all the information the subject possesses about his or her own present health, health behaviour, or family background, among other things. ${ }^{24}$ The association between self rated health and external causes mortality could be partly explained by some kind of "risk taking behaviour".

Self ratings of health usually deteriorate with advancing age, ${ }^{25-27}$ and age was an important factor explaining the association between self rated health and mortality, as expected. When assessing their health, people may use their own previous health status or, on the other hand, the health status of their age peers as a reference, which makes the concept of age rather complex.

It is easy to understand that prevalent diseases make one feel unhealthy, and some diseases may later lead to death. ${ }^{13}$ Even so, only a minor part of the association between self rated health and mortality could be explained by pre-existing diseases. Our follow up of about two decades, however, is a long period of time, during which much happens in people's health status. Yet self rated health has shown stronger associations with chronic conditions than acute ones. ${ }^{26}{ }^{28-30}$ The association between self rated health and mortality among men was slightly stronger during the 8 to 13 year follow up than it was during the 18 to 23 year follow up.

The medical history variables used in this paper were self reported. Self reports have proved to be quite reliable as compared with more objective information sources, especially when the health conditions are severe and clearly defined. ${ }^{31}$

In our study, adding serum cholesterol and systolic blood pressure into the model explained a part of the association between self rated health and mortality. High serum cholesterol and blood pressure are commonly known to be risk factors for cardiovascular diseases. Kaplan et $a l^{13}$ found strong relations between self rated health and cardiovascular risk factors, for example, blood pressure, LDL cholesterol, and smoking, unlike Fylkesnes et $a l .^{26}$ If a person knows he or she has one or the other of these "silent" risk factors, that might influence his or her self assessments of health even without a prevalent disease. ${ }^{32}$ However, among those who have no related disease and are ignorant of their risk factors, blood pressure and cholesterol level should have no effect on self rated health. ${ }^{83}$

Obesity is a controversial predictor of death. ${ }^{34}$ According to a recent paper ${ }^{38}$ both underweight and obesity were associated with poor self rated health among young people. Smoking, an undisputed mortality risk, was associated with poor health ratings among all age groups in that study.

Socioeconomic status is associated with health, self reports of health, and mortality, which has been showed in different countries, for example, Finland, ${ }^{27} 3940$ Scandinavian
KEY POINTS

- Self rated health is a strong predictor of subsequent mortality among both men and women.

- Medical history, cardiovascular risk factors, and educational attainment explain only a part of the association between self rated health and mortality.

- A gradient can be found from "good" through "average" to "poor" self rated health in relation to all cause as well as cardiovascular mortality.

- The predictive power of self rated health confirms the importance of people's self reports of health.

countries, ${ }^{41-45}$ Britain, ${ }^{41}$ 42 46-50 Ireland, ${ }^{51}$ Germany, ${ }^{5253}$ the Netherlands, ${ }^{54}$ the United States, ${ }^{55-57}$ and Australia. ${ }^{58}{ }^{59}$ In many countries education, in particular, has been found to be a powerful factor determining health outcomes. ${ }^{6061}$ High education is also strongly associated with good self reported health. ${ }^{27}{ }^{62}$ Thus the explanatory power of education in our models was possibly smaller than one would have expected. The other possibly education dependent variables, however, may have explained part of this variable's effect. As a measure of socioeconomic status, education is individual and does not change over the course of life as occupations and income often do, and measurement by education avoids the problems of comparability caused by unemployment. $^{60}$

When large groups of people are assessed, we have to bear in mind the variation between individuals among the population. Certain conditions or health behaviour do not lead to death in a similar manner for all people. In addition, the concept of "good" health has many dimensions ${ }^{63-65}$ that vary, for example, by age, cultural background, ${ }^{66-68}$ and possibly by sex. Furthermore, even for a given individual the concept of "good" health may be context bound. ${ }^{69}$ Older people may tend to rate their general health referring to health problems, whereas younger subjects more frequently use health behaviour as a reference. ${ }^{1}$ Self rated health has been found to be associated with physical functioning among men, but more closely among women with subjective health variables, particularly those with painful symptoms. ${ }^{70}$ Thus the mechanisms by which self rated health predicts mortality are necessarily not the same among different subgroups of the population. Self rated health is, however, a unique tool for population surveys, although we do not yet fully understand its contents and the ways through which it is associated with future health events. The predictive power of self rated health confirms the importance of self reports of health-that is, what people say about themselves to health professionals.

In conclusion, self rated health was a strong predictor of mortality in a randomly selected population cohort in eastern Finland, and its predictive power was only partly explained by a 
variety of items from the medical history, cardiovascular disease risk factors, and education. The association existed among both sexes for all cause and cardiovascular mortality and, especially among men, for mortality attributable to external causes. A clear gradient was found from "good" through "average" to "poor" self rated health in relation to all cause and cardiovascular mortality.

Funding: none.

Conflicts of interest: none.

1 Krause NM, Jay GM. What do global self-rated health items measure? Med Care 1994;32:930-42.

2 de Bruin A, Picavet HSJ, Nossikov A, eds. Health interviezw surveys. Towards international harmonization of methods and instruments. Copenhagen: WHO, Regional Publications, European Series No 58, 1996

3 Weinberger M, Darnell JC, Tierney WM, et al. Self-rated health as a predictor of hospital admission and nursing home placement in elderly public housing tenants. $A m \mathcal{F}$ home placement in elderly put

4 Miilunpalo S, Vuori I, Pasanen M, et al. Self-rated health status as a health measure: the predictive value of
self-reported health status on the use of physician services self-reported health status on the use of physician services
and on mortality in the working-age population. $\mathcal{F}$ Clin Epiand on mortality in the

5 Mossey JM, Shapiro E. Self-rated health: a predictor of mortality among the elderly. Am f Public Health 1982;72: $800-8$

6 Kaplan GA, Camacho T. Perceived health and mortality: a nine-year follow-up of the Human Population Laboratory cohort. Am F Epidemiol 1983;117:292-304.

7 Idler EL, Kasl SV, Lemke JH. Self-evaluated health and mortality among the elderly in New Haven, Connecticut, and Iowa and Washington counties, Iowa, 1982-86. Am Epidemiol 1990;131:91-103.

8 Idler EL, Kasl S. Health perceptions and survival: do global evaluations of health status really predict mortality? $\mathcal{F} \mathrm{Ger}$ ontol 1991;46:S55-65.

9 Grant MD, Piotrowski ZH, Chappell R. Self-reported health and survival in the Longitudinal Study of Aging, health and survival in the Longitudinal Stu

10 Wannamethee G, Shaper AG. Self-assessment of health status and mortality in middle-aged British men. Int $\mathcal{F}$ Epidemiol 1991;20:239-45.

11 Pijls LTJ, Feskens EJM, Kromhout D. Self-rated health, mortality, and chronic diseases in elderly men. The $840-8$

12 Appels A, Bosma H, Grabauskas V, et al. Self-rated health and mortality in a Lithuanian and a Dutch population. Soc Sci Med 1996;42:681-9.

13 Kaplan GA, Goldberg DE, Everson SA, et al. Perceived health status and morbidity and mortality: evidence from the Kuopio Ischaemic Heart Disease Risk Factor Study. Int f Epidemiol 1996;25:259-65.

14 Sundqvist J, Johansson S-E. Self reported poor health and low educational level predictors for mortality: a population based follow up study of 39156 people in Sweden. 7 Epidebased follow up study of 39 156 people

15 McGee DL, Liao Y, Cao G, et al. Self-reported health status and mortality in a multiethnic US cohort. Am F Epidemiol 1999;149:41-6.

16 Hays JC, Schoenfeld D, Blaser DG, et al. Global self-rating of health and mortality: hazard in the North Carolina Piedmont. F Clin Epidemiol 1996;49:969-79.

17 Møller L, Kristensen TS, Hollnagel H. Self rated health as a predictor of coronary heart disease in Copenhagen,
Denmark. $\mathcal{F}$ Epidemiol Community Health 1996;50:423-8.

18 Keys A. Coronary heart disease in seven countries. Monograph no 29. New York, NY: American Heart Association, 1970.

19 Puska P, Vartiainen E, Tuomilehto J, et al. Changes in premature deaths in Finland: successful long-term prevention of cardiovascular diseases. Bull World Health Organ 1998;76:419-25.

20 Lundberg O, Manderbacka K. Assessing reliability of a measure of self-rated health. Scand $\mathcal{f}$ Public Health measure of self

21 Martikainen P, Aromaa A, Heliövaara M, et al. Reliability of perceived health by sex and age. Soc Sci Med 1999;48 $1117-22$

22 Manderbacka K, Lahelma E, Martikainen P. Examining the continuity of self-rated health. Int $\mathcal{F}$ Epidemiol 1998;27: 208-13.

23 SAS Institute Inc. SAS/STAT user's guide, version 6, 4th ed. Cary, NC: SAS Institute Inc, 1989

24 Idler EL, Benyamini Y. Self-rated health and mortality: a review of twenty-seven community studies. $\mathcal{F}$ Health Soc Behav 1997;38:21-37.

25 House JS, Kessler RC, Herzog AR, et al. Age, socioeconomic status, and health. Milbank $O$ 1990;68:383-411.

26 Fylkesnes K, Førde OH. The Tromsø study: predictors of self-evaluated health-has society adopted the expanded self-evaluated health-has society adopted
health concept? Soc Sci Med 1991;32:141-6.

27 Heistaro S, Vartiainen E, Puska P. Trends in self-rated health in Finland 1972-1992. Prev Med 1996;25:625-32.
28 Goldstein MS, Siegel JM, Boyer R. Predicting changes in perceived health status. Am F Public Health 1984;74:61114

29 Shadbolt B. Some correlates of self-rated health for Australian women. Am f Public Health 1997;87:951-6.

30 Damian J, Ruigomez A, Pastor V, et al. Determinants of self assessed health among Spanish older people living at home. 7 Epidemiol Community Health 1999;53:412-16.

31 Heliövaara M, Aromaa A, Klaukka T, et al. Reliability and validity of interview data on chronic conditions. F Clin Epidemiol 1993;46:181-91.

32 Lawrence WF, Fryback DG, Martin PA, et al. Health status and hypertension: a population-based study. $f$ Clin Epidemiol 1996;49:1239-45.

33 Kottke TE, Tuomilehto J, Puska P, et al. The relationship of symptoms and blood pressure in a population sample. Int $\mathcal{F}$ Epidemiol 1979;8:355-9.

34 Carmelli D, Zhang H, Swan GE. Obesity and 33-year follow-up for coronary heart disease and cancer mortality. Epidemiology 1997;8:378-83.

35 Dorn JM, Schisterman EF, Winkelstein W Jr, et al. Body mass index and mortality in a general population sample of Epidemiol 1997;146:919-31.

36 Bender R, Trautner C, Spraul M, et al. Assessment of excess mortality in obesity. Am f Epidemiol 1998;147:42-8.

37 Diehr P, Bild DE, Harris TB, et al. Body mass index and mortality in nonsmoking older adults: the Cardiovascular Health Study. Am F Public Health 1998;88:623-9.

38 Manderbacka K, Lundberg O, Martikainen P. Do risk factors and health behaviours contribute to self-ratings of health? Soc Sci Med 1999;48:1713-20.

39 Häkkinen U. The production of health and the demand for health care in Finland. Soc Sci Med 1991;33:225-37.

40 Pekkanen J, Tuomilehto J, Uutela A, et al. Social class, health behaviour, and mortality among men and women in eastern Finland. BMF 1995;311:589-93.

41 Lundberg O. Class and health: comparing Britain and Sweden. Soc Sci Med 1986;23:511-17.

42 Vågerö D, Lundberg $O$. Health inequalities in Britain and Sweden. Lancet 1989;ii:35-6.

43 Rahkonen O, Lahelma E, Karisto A, et al. Persisting health inequalities: social class differentials in illness in the Scandinavian countries. F Public Health Policy 1993;14:66-81.

44 Lahelma E, Manderbacka K, Rahkonen O, et al. Comparisons of inequalities in health: evidence from national surveys in Finland, Norway and Sweden. Soc Sci Med 1994;38:517-24.

45 Osler M, Klebak S. Social differences in health in an affluent Danish county. Scand F Soc Med 1998;26:289-92.

46 Blaxter $M$. Evidence of inequality in health from a national survey. Lancet 1987;ii:30-3.

47 Davey Smith G, Hart C, Blane D, et al. Lifetime socioeconomic position and mortality: prospective observational study. BMF 1997;314:547-52.

48 Hemingway $\mathrm{H}$, Nicholson A, Stafford $\mathrm{M}$, et al. The impact of socioeconomic status on health functioning as assessed by the SF-36 questionnaire: the Whitehall II Study. $A m \mathcal{F}$ Public Health 1997;87:1484-90.

49 Power C, Hertzman C, Matthews S, et al. Social differences in health: life-cycle effects between ages 23 and 33 in the 1958 British birth cohort. Am f Public Health 1997;87: 1499-503.

50 Hart CL, Davey Smith G, Blane D. Inequalities in mortality by social class measured at 3 stages of the lifecourse. $A m \mathcal{F}$ Public Health 1998;88:471-4.

51 O'Shea E. Male mortality differentials by socioeconomic group in Ireland. Soc Sci Med 1997;45:803-9.

52 Helmert U, Shea S. Social inequalities and health status in Western Germany. Public Health 1994;108:341-56.

53 Geyer S, Peter R. Occupational status and all-cause mortality. A study with health insurance data from Nordrhein-Westfalen, Germany. Eur $f$ Public Health 1999;9:114-18

54 Gijsbers van Wijk CMT, Kolk AM, van den Bosch WJHM, et al. Male and female health problems in general practice: the differential impact of social position and social roles. Soc Sci Med 1995;40:597-611.

55 Sorlie PD, Backlund E, Keller JB. US mortality by economic, demographic, and social characteristics: the National Longitudinal Mortality Study. Am f Public Health 1995;85:949-56.

56 Kaplan GA, Pamuk ER, Lynch JW, et al. Inequality in income and mortality in the United States: analysis of mortality and potential pathways. BMF 1996;312:999-1003.

57 Barnett E, Armstrong DL, Casper ML. Social class and premature mortality among men: a method for state-based surveillance. Am 7 Public Health 1997;87:1521-5.

58 Taylor R, Quine S, Lyle D, et al. Socioeconomic correlates of mortality and hospital morbidity differentials by Local Government Area in Sydney 1985-1988. Aust f Public Health 1992;16:305-14.

59 Lawson JS, Black D. Socioeconomic status: the prime indicator of premature death in Australia. F Biosoc Sci 1993;25: $539-52$

60 Valkonen T. Adult mortality and level of education: a comparison of six countries. In: Fox AJ, ed. Health inequalities in European countries. Aldershot: Gower, 1989:142-60.

61 Winkleby MA, Jatulis DE, Frank E, et al. Socioeconomic status and health: how education, income, and occupation contribute to risk factors for cardiovascular disease. $A m \mathcal{F}$ Public Health 1992;82:816-20. 
62 Lahelma E, Rahkonen O, Huuhka M. Changes in the social patterning of health? The case of Finland. Soc Sci Med patterning of healt

63 Ware JE. Standards for validating health measures: definition and content. F Chron Dis 1987;40:473-80.

64 Litva A, Eyles J. Health or healthy: why people are not sick in a southern Ontarian town. Soc Sci Med 1994;39:1083-91.

65 Smith AMA, Shelley JM, Dennerstein L. Self-rated health: biological continuum or social discontinuity? Soc Sci Med 1994;39:77-83

66 Angel R, Gronfein W. The use of subjective information in statistical models. American Sociological Review 1988;53 464-73.
67 Honeyman PT, Jacobs EA. Effects of culture on back pain in Australian aboriginals. Spine 1996;21:841-3.

68 Shetterly SM, Baxter J, Mason LD, et al. Self-rated health among Hispanic vs non-Hispanic white adults: the San Luis Valley Health and Aging Study. Am f Public Health 1996;86:1798-801.

69 Jylhä $M$. Self-rated health revisited: exploring survey interview episodes with elderly respondents. Soc Sci Med 1994;39:983-90.

70 Kumpusalo E, Pekkarinen H, Neittaanmäki L, et al. Identification of health status dimensions in a working-age population. An exploratory study. Med Care 1992;30:392-9.

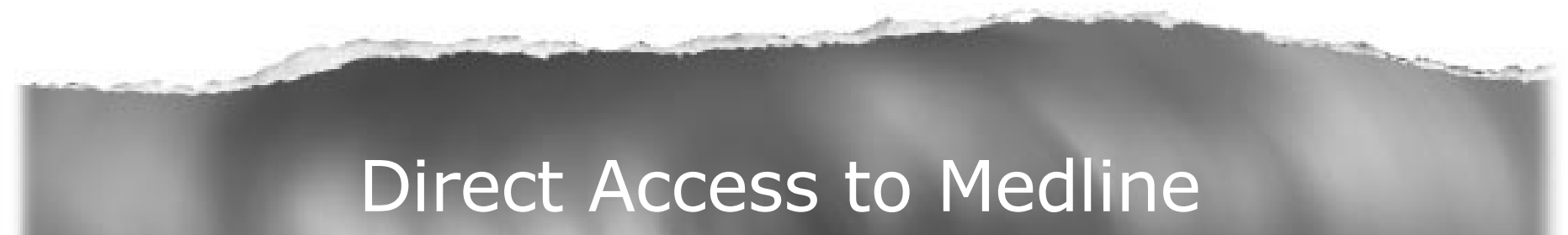

\section{Medline}

Link to Medline from the homepage and get straight into the National Library of Medicine's premier bibliographic database. Medline allows you to search across 9 million records of bibliographic citations and author abstracts from approximately 3,900 current biomedical journals.

www.jech.com 